\title{
Proton magnetic resonance spectra of plasma- deposited inorganic thin films
}

\author{
J. A. Reimera) and R. W. Vaughan ${ }^{\text {b) }}$ \\ Division of Chemistry and Chemical Engineering, California Institute of Technology, Pasadena, California 91125
}

J. C. Knights and R. A. Lujan

Xerox Palo Alto Research Center, 3333 Coyote Hill Road. Palo Alto, California 94304

(Received 11 March 1981; accepted 20 March 1981)

Proton magnetic resonance data are presented for the hydrogen alloys of plasma-deposited amorphous boron, carbon, silicon carbide, and silicon nitride. Linewidth and lineshape analysis leads to the conclusion that hydrogen nuclei are clustered in a-Si/C:H, a-C:H, and a-Si/C:H. Both a-Si/C:H and a-C:H data show that the hydrogen exists in two phases. Modeling of linewidths in a-Si/C:H indicates that the two phases are heavily hydrogenated carbon clusters imbedded in a weakly hydrogenated a-Si lattice. Finally, evidence is presented for the presence of motionally narrowed hydrogen spectra in a-Si/N:H, a-B:H, and a-C:H. It is suggested that the hydrogen nuclei giving rise to these spectra are associated with disorder modes.

PACS numbers: 76.60. $-\mathrm{k}, 61.16 . \mathrm{Hn}, 68.60 .+\mathrm{q}$

Inorganic thin films prepared either by plasma-deposition or reactive sputtering techniques have attracted a great deal of attention recently ${ }^{1}$ because of their technological importance. Plasma deposited silicon nitrides have proven attractive for use as passivation layers in high reliability silicon integrated circuits, and amorphous silicon has been doped successfully to form $p, n$ and Schottky barrier junctions, as well as solar cells. ${ }^{2}$ The role of hydrogen in these films is not well understood, although it is generally accepted that hydrogen passivates dangling bond intrinsic defects and thus decreases the density of states in the gap. ${ }^{2-4}$

It has recently been show $n^{5}$ that proton magnetic resonance data reveal unique information on the degree of clustering and intermingling of local hydrogen bonding environments in amorphous plasma-deposited silicon-hydrogen films. Hydrogen also plays an important role in the properties of other films such as silicon nitride, ${ }^{3,6-9}$ silicon carbide, ${ }^{3,10,11}$ carbon, ${ }^{4,12-14}$ and boron. It is the purpose of this article to report two-component dipolar broadened magnetic resonance spectra of the hydrogen alloys of these plasma-deposited amorphous substances. It will be shown that data for a-C:H, a-Si/N:H, and a-Si/C:H lead to the conclusion that the hydrogen nuclei are clustered. In addition, the data for a-C:H and a-Si/C:H show direct evidence for two phase compositional inhomogeneity, where molding of local bonding environments in a-Si/C:H suggests that the two phases are due to heavily hydrogenated carbon clusters imbedded in a weakly hydrogenated a-Si lattice. Furthermore, temperature dependent data for a-B:H, a-Si/N:H, and a-C:H indicate that a small fraction of the protons in these films have spectra which are motionally narrowed. We associate them with disorder modes in the lattice.

The samples were prepared by deposition ${ }^{15}$ under the conditions detailed in Table I. All samples were deposited onto $\sim 2$ in. diam aluminum foil substrates in thicknesses ranging from 1 to $100 \mu$ resulting in sample masses in the range of
5-100 mg after removal of the substrates with dilute acid etch. Silicon/carbon and silicon/nitrogen ratios were determined using Rutherford backscattering. A pulse NMR spectrometer ${ }^{16}$ was used at an operating frequency of $56.4 \mathrm{MHz}(1.3$ Tesla). The resonance techniques and the least-squares fitting of the observed lineshapes to the sum of a Gaussian (broad component) and a Lorentzian (narrow component) have been described previously. ${ }^{5}$

Figure 1 shows a comparison of spectra at room temperature and $125 \mathrm{~K}$ for the samples described in Table $\mathrm{I}$. The observed linewidths reflect contributions from (i) homonuclear dipolar interactions, (ii) heteronuclear dipolar interactions, and (iii) chemical shift interactions. When multiple pulse cycles $^{17-19}$ were applied (which remove the homonuclear dipolar broadening), the lines were narrowed by a factor of 10-30. Thus for a-C:H, a-Si/C:H, and a-Si/N:H, the homonuclear dipolar interaction is the dominant broadening mechanism in the proton spectra. In a-B:H, the heteronuclear dipolar interaction due to nearby ${ }^{10} \mathrm{~B}$ and ${ }^{11} \mathrm{~B}$ nuclei was estimated ${ }^{20}$ and was found to be as large or larger than the homonuclear dipolar interaction.

The spectra for all the samples may be decomposed into at least two components. Multicomponent lineshapes in these films may arise from the following situations: (i) motion in a domain or at a defect site which decouples spin-spin communication ${ }^{20}$ from the rest of the dipolar reservoir, (ii) the existence of spatially-isolated ( $\geq 8 \AA)^{21}$ dipolar reservoirs with differing densities of spins such that there is no spin-spin communication between them, or (iii), both (i) and (ii). The first case has been observed in partially crystalline polyethylene $^{22}$ and case (ii) in amorphous silicon-hydrogen films. ${ }^{5}$ Effects on the lineshape due to motion may often be removed by reducing the temperature, hence, cases (i) and (ii) may be readily distinguished. Inspection of Fig. 1 and Table II shows that at low temperature, where motional narrowing is not expected, both a-C:H and a-Si/C:H spectra still exhibit two- 
TABLE I. Deposition conditions.

\begin{tabular}{|c|c|c|}
\hline Sample conditions ${ }^{\mathbf{a}}$ & $\begin{array}{c}\text { Hydrogen content } \\
\text { At. } \% \\
\end{array}$ & $\begin{array}{l}\text { Molecular } \\
\text { formula }\end{array}$ \\
\hline $\begin{array}{l}5 \% \mathrm{~B}_{2} \mathrm{H}_{6} / \mathrm{He}(\mathrm{C}) \\
10 \mathrm{~W}, 25^{\circ} \mathrm{C}\end{array}$ & 25.1 & $\mathrm{a}-\mathrm{B} .75 \mathrm{H}_{.25}$ \\
\hline $\begin{array}{l}5 \% \mathrm{~B}_{2} \mathrm{H}_{6} / \mathrm{He}(\mathrm{A}) \\
10 \mathrm{~W}, 230^{\circ} \mathrm{C}\end{array}$ & $20.6^{f}$ & $\mathrm{a}-\mathrm{B} .79 \mathrm{H}_{21}$ \\
\hline $\begin{array}{l}100 \% \mathrm{C}_{2} \mathrm{H}_{2}(\mathrm{~A}) \\
5 \mathrm{~W}, 230^{\circ} \mathrm{C}\end{array}$ & 35.2 & $\mathrm{a}-\mathrm{C}_{.65} \mathrm{H}_{.35}$ \\
\hline $\begin{array}{l}13 \% \mathrm{SiH}_{4} / \mathrm{C}_{2} \mathrm{H}_{2}(\mathrm{~A}) \\
2 \mathrm{~W}, 230^{\circ} \mathrm{C}^{\mathrm{e}}\end{array}$ & 22.7 & $\mathrm{a}-\mathrm{Si} .20 \mathrm{C} .57 \mathrm{H}_{.23}$ \\
\hline $\begin{array}{l}26 \% \mathrm{SiH}_{4} / \mathrm{C}_{2} \mathrm{H}_{2}(\mathrm{~A}) \\
2 \mathrm{~W}, 230^{\circ} \mathrm{C}^{\mathrm{d}}\end{array}$ & $38.2^{\mathrm{f}}$ & $\mathrm{a}-\mathrm{Si} .{ }_{.26} \mathrm{C} .36 \mathrm{H} .38$ \\
\hline $\begin{array}{l}\mathrm{NH}_{3} / \mathrm{N}_{2} / \mathrm{SiH}_{4} \text { flow(A) } \\
\text { Flow rates } 100 / 50 / 6 \mathrm{sccm} \\
10 \mathrm{~W}, 300^{\circ} \mathrm{C}\end{array}$ & 23.0 & $\mathrm{a}-\mathrm{Si}_{.31} \mathrm{~N}_{.46} \mathrm{H}_{.23}^{\mathrm{c}}$ \\
\hline
\end{tabular}

The conditions refer to percentage gas in mixture, net if power into matching network, substrate temperature: $(A)$ refers to deposition on the grounded electrode (Anode) and (C) refers to the if hot (Cathode) electrode.

betermined from proton spin density, sample weight, and $\mathrm{Si} / \mathrm{C}$ or $\mathrm{Si} / \mathrm{N}$ ratios.

c $\mathrm{Si} / \mathrm{N}$ ratio determined by Rutherford backscattering.

${ }^{d} \mathrm{Si} / \mathrm{C}$ ratio determined by $\mathrm{Rutherford} \mathrm{backscattering.}$

e $\mathrm{Si} / \mathrm{C}$ ratio estimated from the Rutherford backscattering results for the $26 \% \mathrm{SiH}_{4} / \mathrm{C}_{2} \mathrm{H}_{2}$ sample and the ratio of silane percentages.

'Spectra not shown in Fig. 1.

component behavior. In a-Si/ $\mathrm{N}: \mathrm{H}$, a-B:H, and a-C:H, a small fraction of the protons have lineshapes that do appear to be motionally narrowed at room temperature. However, this fraction accounts for no more than $3 \%$ of the total proton spins. Hence, we conclude that a-Si/C:H is best described by case (ii), a-B:H and a-Si/N:H by case (i), and a-C:H by case (iii). The low temperature spectra for $\mathrm{a}-\mathrm{B}: \mathrm{H}$ and $\mathrm{a}-\mathrm{Si} / \mathrm{N}: \mathrm{H}$ show no evidence for case (ii); however, we shall present evidence suggesting that the hydrogen nuclei in a-Si/N:H are clustered. In a-B:H we estimate ${ }^{20}$ the heteronuclear dipolar interaction to be $\sim 70 \mathrm{kHz}$, hence no structural information is expected from proton lineshapes.

Further insight into the distribution of hydrogen can be derived from analysis of the low temperature data shown in Fig. 1 and Table II according to models for local proton configurations. The homonuclear and heteronuclear dipolar

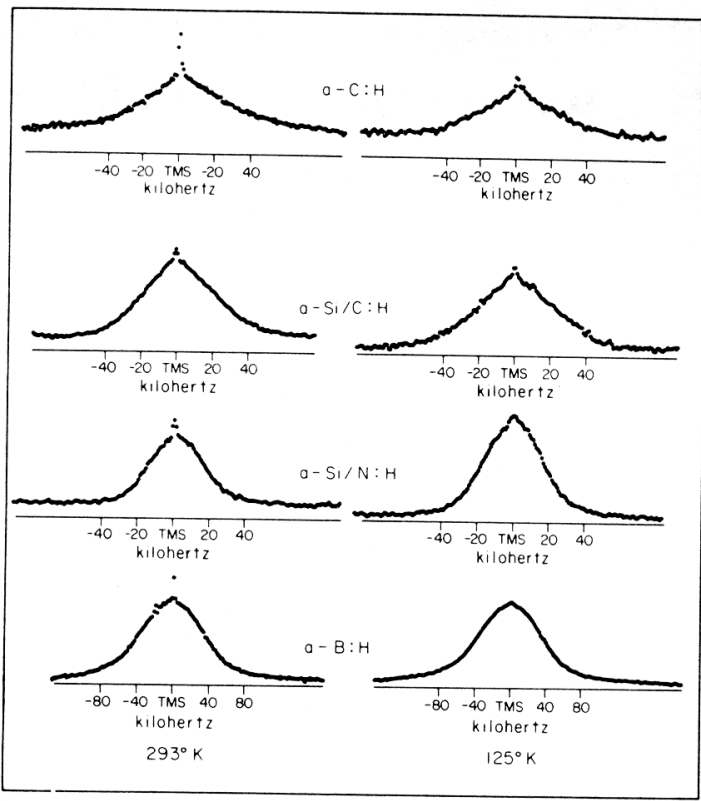

FIG. 1. Proton free-induction decay spectra for, from top to bottom, amorphous carbon, silicon carbide, silicon nitride, and boron (cathode). Details of sample preparation conditions are shown in Table I. On the left are spectra at room temperature, on the right, at $125 \mathrm{~K}$

interactions in polycrystalline or amorphous solids give rise to Gaussian lineshapes whose second moments are given by, respectively, ${ }^{20}$

$$
\begin{gathered}
M_{2}{ }^{I I}=3 / 5{\gamma_{1}}^{4} \hbar^{2} l(l+1) \sum_{j} 1 / r_{i j}{ }^{6}, \\
M_{2}{ }^{I S}=4 / 15 \gamma_{I}{ }^{2} \gamma_{S}{ }^{2} \hbar^{2} S(S+1) \sum_{j} 1 / r_{i j}{ }^{6},
\end{gathered}
$$

where $\gamma_{I}$ is the nuclear gyromagnetic ratio for a nucleus of spin $l$ and $r_{i j}$ is the internuclear distance between spins $i$ and $j$. For a-C;H, a-Si/C:H, and a-Si/N:H, two types of proton configurations to which Eq. (1) simply applies have been considered. The first is one of local clustering into configuration such as $\mathrm{CH}_{3},\left(\mathrm{CH}_{2}\right)_{n},\left(\mathrm{SiH}_{2} \mathrm{CH}_{2}\right)_{n}, \mathrm{SiNH}_{2}$, and a hydrogenated $[111] c$-carbon surface. The corresponding $\mathrm{Si}-\mathrm{H}$ clustering has previously been calculated. ${ }^{5}$ The results of these

\begin{tabular}{|c|c|c|c|c|c|c|c|}
\hline \multicolumn{8}{|c|}{ Hydrogen distribution } \\
\hline \multirow[b]{2}{*}{ Sample } & & \multicolumn{2}{|c|}{ Broad } & \multicolumn{2}{|c|}{ Narrow } & \multicolumn{2}{|c|}{ Linewidth (FWHM, $\mathrm{kHz}$ ) } \\
\hline & & $\%$ & At. \% & $\%$ & At. $\%$ & Broad & Narrow \\
\hline \multirow[t]{2}{*}{$\mathrm{a}-\mathrm{C}_{.65} \mathrm{H}_{35}$} & $293 \mathrm{~K}$ & 93.5 & $32.7 \pm .4$ & 6.5 & $2.3 \pm .3$ & $78.4 \pm 2.6$ & $1.6 \pm .7$ \\
\hline & $130 \mathrm{~K}$ & 91.1 & $32.1 \pm .4$ & 8.9 & $3.1 \pm .4$ & $76.8 \pm 2.8$ & $6.6 \pm .2$ \\
\hline a-B $.75 H_{.25}$ & $293 \mathrm{~K}$ & 98.9 & $24.8 \pm .1$ & 1.1 & $0.3 \pm .1$ & $118 \pm 3$ & $1.8 \pm .1$ \\
\hline (cathode) & $124 \mathrm{~K}$ & 98.7 & $24.8 \pm .1$ & 1.3 & $0.3 \pm .1$ & $121 \pm 3$ & $11.7 \pm .6$ \\
\hline $\begin{array}{l}\text { a-B. } .79 \mathrm{H}_{.21^{2}} \\
\text { (anode) }\end{array}$ & $293 \mathrm{~K}$ & 98.5 & $20.7 \pm .1$ & 1.5 & $0.3 \pm .1$ & $83.7 \pm 1.4$ & $3.6 \pm .7$ \\
\hline \multirow[t]{2}{*}{$\mathrm{a}-\mathrm{Si}{ }_{31} \mathrm{~N}_{.46} \mathrm{H}_{.21}$} & $293 \mathrm{~K}$ & 97.0 & $22.3 \pm .2$ & 3.0 & $0.7 \pm .2$ & $35.1 \pm .3$ & $2.2 \pm .1$ \\
\hline & $124 \mathrm{~K}$ & 97.8 & $22.5 \pm .2$ & 2.2 & $0.5 \pm .2$ & $55.6 \pm .2$ & $6.0 \pm .2$ \\
\hline \multirow[t]{2}{*}{$\mathrm{a}-\mathrm{Si} .20 \mathrm{C} .57 \mathrm{H}_{.23^{b}}$} & $293 \mathrm{~K}$ & 94.5 & $21.5 \pm .3$ & 5.5 & $1.2 \pm .3$ & $69.0 \pm .3$ & $7.4 \pm .3$ \\
\hline & $126 \mathrm{~K}$ & 95.3 & $21.6 \pm .3$ & 4.7 & $1.1 \pm .3$ & $78.4 \pm .4$ & $7.0 \pm .3$ \\
\hline $\mathrm{a}-\mathrm{Si}{ }_{.26} \mathrm{C}_{.36} \mathrm{H}_{.38^{2}}$ & $293 \mathrm{~K}$ & 98.1 & $37.5 \pm .3$ & 1.9 & $0.7 \pm .3$ & $45.6 \pm .4$ & $1.9 \pm .2$ \\
\hline
\end{tabular}

TABLE II. NMR results.

Spectra not shown in Fig. 1.

b Estimated molecular formula (see Table I). 
TABLE III. Narrow component analysis.

\begin{tabular}{|c|c|c|c|}
\hline Sample & $\begin{array}{c}\text { At. } \% \\
\text { narrow }\end{array}$ & $\begin{array}{c}\text { Observed } \\
\text { FWHM } \\
\text { narrow } \\
(\mathrm{kHz})\end{array}$ & $\begin{array}{l}\text { Calculated } \\
\text { homogeneous } \\
\text { width } \\
(\mathrm{kHz})\end{array}$ \\
\hline $\mathbf{a}-\mathrm{C}: \mathrm{H}^{\mathbf{b}}$ & 3.1 & 6.6 & 1.7 \\
\hline $\mathrm{a}-\mathrm{Si} .{ }_{.26} \mathrm{C}_{.36} \mathrm{H}_{.38}$ & 0.7 & 1.9 & 0.4 \\
\hline $\mathrm{a}-\mathrm{Si} .20 \mathrm{C}_{.57} \mathrm{H}_{.23}{ }^{\mathrm{d}}$ & 1.2 & 7.0 & 0.6 \\
\hline $\mathrm{a}-\mathrm{Si}_{.31} \mathrm{~N}_{.46} \mathrm{H}_{.23}$ & $23.0^{\mathrm{c}}$ & 55.6 & 12.9 \\
\hline
\end{tabular}

a Calculated with use of Eq. (1).

b The low temperature values were chosen to eliminate motion effects.

c Total hydrogen content.

'Estimated molecular formula (see Table I).

calculations and an estimate ${ }^{23}$ of the linewidth (FWHM) for isolated $\mathrm{CH}_{2}$ are as follows: $\mathrm{CH}_{2}, 33.1 \mathrm{kHz}\left(\mathrm{SiH}_{2}, 13.5 \mathrm{kHz}\right)$; $\mathrm{CH}_{3}, 46.9 \mathrm{kHz}\left(\mathrm{SiH}_{3}, 19.2 \mathrm{kHz}\right) ;\left(\mathrm{CH}_{2}\right)_{n}, 44.1 \mathrm{kHz}\left(\mathrm{SiH}_{2}\right)_{n}$, $17.1 \mathrm{kHz} ;\left(\mathrm{SiH}_{2} \mathrm{CH}_{2}\right)_{\mathrm{n}}, 36.1 \mathrm{kHz}$; and $\mathrm{C}[111], 57.4 \mathrm{kHz}$ $\left(\mathrm{Si}[111], 23.5 \mathrm{kHz}\right.$ ) and $\mathrm{SiNH}_{2}, 37.8 \mathrm{kHz}$. Given the sensitivity of the calculation to small changes in internuclear distances and the errors involved in the fitting procedures, we conclude that any of the local configurations on carbon could give rise to the broad component in both a-C:H and a-Si/C:H spectra. Since the width of the broad component is $>45 \mathrm{kHz}$ in both of the a-Si/C:H samples, and the broadest component expected for protons clustered on silicon is $23.5 \mathrm{kHz}$ and on $\left(\mathrm{SiH}_{2} \mathrm{CH}_{2}\right)_{n}$ is $36.1 \mathrm{kHz}$, we conclude that for silicon carbide the broad line is due to predominantly "polyacetylene" type environments. This is especially true for the higher carbon content sample where the observed broad component linewidth is identical to that of amorphous carbon. This implies that the spatial inhomogeneity in the protons is reflective of carbon clusters which are heavily hydrogenated and imbedded in a weakly hydrogenated amorphous silicon lattice.

The second situation to which Eq. (1) may be simply applied is one where the spins are distributed uniformly on a cubic lattice whose spacing is equal to the inverse cube root of the spin density. The results of applying this model for Eq. (l) to the narrow component of the $\mathrm{a}-\mathrm{Si} / \mathrm{C}: \mathrm{H}$ and $\mathrm{a}-\mathrm{C}: \mathrm{H}$ lineshapes as well as the total lineshape in a-Si/N:H are shown in Table III. These calculations show that the narrow component of a-Si/C:H and a-C:H, as well as the total lineshape in a-Si/N:H, is broader than would be predicted for a uniform distribution of protons. Local clustering of hydrogen on nitrogen atoms is sufficient to explain the observed linewidth in a-Si/N:H. However, in a-Si/C:H and a-C:H the clustering in the narrow component is not dominated by local multiply bonded species such as $\mathrm{SiH}_{x}$ or $\mathrm{CH}_{x}$ since those species yield much larger linewidths. We conclude that the narrow component is composed primarily of monohydride species $(\mathrm{CH}$ or $\mathrm{SiH}$ ) distributed at random. ${ }^{27}$

The room temperature spectra of a-C:H, a-Si/N:H, and a-B:H all show a small narrow component that increases in width as the temperature is decreased. Since these components do not decrease in intensity with extended evacuation of the samples, they are not due to adsorbed gases. We conclude that they are motionally narrowed ${ }^{17}$ spectra due to hydrogen nuclei which are indigenous to the films. Estimates of the dipolar broadening, including the effects of motion, ${ }^{17,24}$ in rotating local bonding configurations such as methyl groups yield values much larger than those observed. We suggest that these motionally narrowed lines correspond to hydrogen nuclei rapidly moving in a defect site or disorder mode. The existence of hydrogen-containing disorder modes has recently been proposed ${ }^{25}$ in a-Si:H in order to explain the temperature and field dependence of proton spin-lattice relaxation, $T_{1}$, as well as other relaxation measurements. ${ }^{26}$ Their presence in a- $\mathrm{C}: \mathrm{H}, \mathrm{a}-\mathrm{Si} / \mathrm{N}: \mathrm{H}$, and $\mathrm{a}-\mathrm{B}: \mathrm{H}$ indicate that such modes may be ubiquitous in hydrogen containing amorphous materials. The relationship between these modes and defects affecting optical properties warrants further investigation.

In conclusion, we have shown that for a series of plasmadeposited inorganic thin films, hydrogen is spatially inhomogeneous on two levels. The first consists of hydrogen clustering which we have observed in a-C:H, a-Si/C:H, and a$\mathrm{Si} / \mathrm{N}: \mathrm{H}$. We conclude that the second, observed in a-C:H and a-Si/C:H, is a two-phase compositional inhomogeneity. Furthermore, we have presented evidence that in a-Si/C:H the inhomogeneity is due to heavily hydrogenated carbon clusters imbedded in a weakly hydrogenated a-Si lattice. Finally, we have observed a small fraction of protons whose spectra are of motionally narrowed hydrogen nuclei. We attribute these to disorder modes within the lattices of $\mathrm{a}-\mathrm{B}: \mathrm{H}$, $\mathrm{a}-\mathrm{C}: \mathrm{H}$, and $\mathrm{a}-\mathrm{Si} / \mathrm{N}: \mathrm{H}$. These results imply that film microstructure, compositional inhomogeneity, and rapidly moving hydrogen nuclei may be important in understanding both defect structures and optical properties in plasma-deposited inorganic thin films.

Acknowledgments: The authors thank S. I. Chan and T. M. Duncan for helpful comments on the manuscript and T. $W$. Sigmon for assistance with the Rutherford backscattering analysis. This work was supported by the National Science Foundation under Grant No. DMR 77-21394.

"Current address: IBM T. J. Watson Research Center, Yorktown Hts., NY 10598.

bDeceased.

${ }^{1}$ A. R. Reinberg, Ann. Rev. Mat. Sci. 9, 341 (1979).

${ }^{2}$ H. Fritzsche, C. C. Tsai, and P. Persans, Solid State Technol. 21, 55 (1978).

${ }^{3}$ D. A. Anderson and W. E. Spear, Phil. Mag, 35, 1 (1977).

${ }^{4} D$. A. Anderson, Phil. Mag. 35, 17 (1977).

5J. A. Reimer, R. W. Vaughan, and J. C. Knights, Phys. Rev. Lett. 44, 193 (1980).

${ }^{6}$ E. A. Taft, J. Electrochem. Soc.: Solid State Science 118, 1341 (1971).

${ }^{7}$ H. R. Philipp, ibid, 120, 295 (1973).

${ }^{8}$ P. S. Peercy, H. J. Stein, B. L. Doyle, and S. T. Picraux, J. Electron. Mater. 8, 11 (1979).

${ }^{9}$ A. K. Sinha, Solid State Technol. 23, 133 (1980).

${ }^{10} \mathrm{D}$. Engemann, R. Fischer, and J. Knecht, Appl. Phys. Lett. 32, 567 (1978).

${ }^{11}$ A. Guivarich, J. Richard, M. LeConteller, E. Ligeon, and J. Fontenille, J. Appl. Phys. 51, 2167 (1980).

12 M. R. Havens, K. G. Mayhan, and W. J. James, J. Appl. Polym. Sci. 22, 2793 (1975).

${ }^{13}$ M. R. Havens, K. G. Mayhan, and W. J. James, ibid, 22, 2799 (1978).

${ }^{14}$ A. Moshonov and Y. Avny, J. Appl. Polym. Sci. 25, 771 (1980).

${ }^{15}$ R. A. Street, J. C. Knights, and D. K. Biegelsen, Phys. Rev. B 18, 1880 (1978).

${ }^{16 R}$. W. Vaughan, D. D. Elleman, L. M. Stacey, W.-K. Rhim, and J. W. Lee, Rev. Sci. Instrum. 43, 1356 (1972). 
${ }^{17} \mathrm{C}$. P. Slichter, Princtples of Magnetic Resonance (Springer-Verlag, Berlin, 1978).

${ }^{18} \mathrm{M}$. Mehring, in NMR Basic Principles and Progress, edited by P. Diehl, E. Fluck, and R. Kosfeld (Springer-Verlag, Berlin, 1976).

${ }^{19} \mathrm{U}$. Haeberlen, in Advances in Magnetic Resonance Supp. 1, edited by J. S. Waugh (Academic, New York, 1976).

${ }^{20} \mathrm{~A}$. Abragam, The Principles of Nuclear Magnetism (Oxford, London, 1961).

${ }^{21}$ Ref. 20 shows the probability of mutual spin flips between neighbors to be $\sim\left(M_{2}\right)^{1 / 2} / 30$.
${ }^{22}$ R. G. Pembleton, R. C. Wilson, and B. C. Gerstein, J. Chem. Phys. 66, 5133 (1977).

${ }^{23}$ Both $\mathrm{CH}_{2}$ and $\mathrm{SiH}_{2}$ give rise to Pake doublets. In an amorphous matrix such doublets would be expected to broaden considerably and the values of 13.6 and $33.1 \mathrm{kHz}$ for $\mathrm{SiH}_{2}$ and $\mathrm{CH}_{2}$, respectively, are an approximate measure of the linewidth.

${ }^{24}$ H. S. Gutowsky and G. E. Pake, J. Chem. Phys. 18, 162 (1950).

${ }^{25}$ W. E. Carlos and P. C. Taylor, Phys. Rev. Lett 45, 358 (1980).

26]. A. Reimer, R. W. Vaughan, and J. C. Knights, Phys. Rev. B (in press).

${ }^{27}$ J. A. Reimer, R. W. Vaughan, and J. C. Knights (to be published). 